\title{
HIV infection and in-hospital mortality at an academic hospital in South Africa
}

\author{
Karen Zwi, John Pettifor, Neil Soderlund, Tammy Meyers
}

\begin{abstract}
Aim-To document the impact that rapid increases in HIV infection in hospitalised children at Chris Hani Baragwanath Hospital has had on in-hospital mortality. Methods-Hospital discharge summaries from January 1992 to the end of 1996 were reviewed.

Results-There were 20733 admissions in the five year period; 7985 (39\%) were tested for HIV. In tested admissions above 15 months of age, $4.9 \%$ were HIV infected in 1992 , increasing to $35 \%$ in 1996 . Under 15 months of age, $9 \%$ of tested admissions were positive in 1992 , increasing to $46 \%$ in 1996. The proportion of all hospital deaths occurring in children considered HIV infected (ELISA testing together with clinical features if $\mathbf{1 5}$ months or younger) increased from $6.7 \%$ in 1992 to $46.1 \%$ in 1996 ( $<$ < 0.001). In-hospital mortality for all children increased by $21 \%$ from $4.3 \%$ in 1992 to $5.2 \%$ in 1996. Mortality rates declined in uninfected children from $5.4 \%$ in 1992 to $4.5 \%$ in $1996\left(\chi^{2}\right.$ trend 3.3; $\mathbf{p}=0.06)$.

Conclusion-The mortality rate of children has increased at Chris Hani Baragwanath Hospital as a result of HIV infection. Almost half the deaths were HIV related in 1996. HIV infection is threatening the advances that have been made on child survival in South Africa over the last few decades.
\end{abstract}

(Arch Dis Child 2000;83:227-230)

Keywords: hospital mortality; HIV infection; AIDS; child mortality; mortality rates; South Africa

South Africa is experiencing a rapidly growing HIV epidemic. In women attending antenatal clinics in the public health service, seroprevalence has risen from $7.9 \%$ in $1994^{1}$ to $22.8 \%$ in $1998 .^{2}$ The age groups with the highest fertility rates in the country, 20-24 and 25-29 year olds, are also those with the highest HIV seroprevalence rates at $26.1 \%$ and $26.9 \%$ respectively. ${ }^{2}$ Furthermore, HIV transmission from mother to child is high, between $26 \%$ and $42 \%$ in South Africa, ${ }^{3}$ resulting in high rates of paediatric HIV infection. Accurate data regarding life expectancy and admission rates in HIV infected children are required for inclusion in economic analyses in order to inform crucial decisions regarding interventions to reduce mother to child transmission.

The impact of HIV on child mortality in less developed nations is the subject of much speculation. ${ }^{4-6}$ It appears that under-five mor- tality rates have been stagnant or rising in several African countries since the 1980s. HIV may be responsible for this in some, but in others the changes have occurred too early in the epidemic for the rise to be attributable to HIV. ${ }^{5}$ The problem of measuring how HIV has affected mortality is compounded as accurate data are least available where HIV seroprevalence is high. Thus, well into the AIDS epidemic, accurate data exist only for a few localised populations. ${ }^{78}$ Hospital data provide an important piece of the jigsaw in that they give an opportunity for accurate and timely information about HIV status and in-hospital mortality, despite the serious limitation in defining the population denominator. We report on a hospital based study, using routine data, which documents the impact of paediatric HIV infection on trends in hospital admissions and in-hospital mortality over a five year period when HIV was rising rapidly in the region. We have previously documented a $24 \%$ increase in admissions as a direct consequence of paediatric HIV, a shift in the age distribution towards that of younger children, increased admissions for pneumonia, gastroenteritis, malnutrition, and tuberculosis, and increased readmission rates. ${ }^{9}$ The effect of paediatric HIV on in-hospital mortality over the time period 1992 to 1996 is presented in this paper. We discuss how the in-hospital mortality rates presented relate to community mortality rates and use the empirical data to speculate the effect paediatric HIV infection rates have had on infant and child mortality rates in the local community.

\section{Methods}

STUDY SITE

Chris Hani Baragwanath (CHB), the academic hospital under study, is situated in greater Johannesburg in the province of Gauteng, South Africa. It serves the densely populated urban township of Soweto and acts as a regional centre for the southern parts of the province. CHB is the only public sector hospital within the Soweto township, although there is fairly easy access to other Johannesburg public sector hospitals. It is the largest hospital in the world, with over 3000 beds and 7000 members of staff. It is not possible to assess accurately where all patients originate as patients living outside the area may give a Soweto address for fear of being referred back to their local hospitals for management.

\section{DISCHARGE SUMMARY REVIEW}

Computerised hospital discharge summaries of general paediatric admissions at Chris Hani Baragwanath Hospital were used to obtain 
Table 1 Paediatric in-hospital mortality and HIV status

\begin{tabular}{|c|c|c|c|c|c|c|c|c|c|c|c|}
\hline & \multirow[b]{2}{*}{$\begin{array}{l}\text { Total no. of } \\
\text { admissions }\end{array}$} & \multicolumn{3}{|c|}{ No. of HIV positive admissions } & \multirow[b]{2}{*}{$\begin{array}{l}\text { Percentage } \\
\text { mortality in } \\
\text { HIV positive } \\
\text { admissions }\end{array}$} & \multirow[b]{2}{*}{$\begin{array}{l}\text { No. of HIV } \\
\text { negative } \\
\text { admissions } \\
\text { (\% of all } \\
\text { admissions) }\end{array}$} & \multirow[b]{2}{*}{$\begin{array}{l}\text { Percentage } \\
\text { mortality in } \\
\text { HIV } \\
\text { negative } \\
\text { admissions }\end{array}$} & \multirow[b]{2}{*}{$\begin{array}{l}\text { No. of } \\
\text { admissions not } \\
\text { tested for HIV } \\
\text { (\% of all } \\
\text { admissions) }\end{array}$} & \multirow[b]{2}{*}{$\begin{array}{l}\text { Percentage } \\
\text { mortality } \\
\text { in untested } \\
\text { admissions }\end{array}$} & \multirow[b]{2}{*}{$\begin{array}{l}\text { Percentage of } \\
\text { annual } \\
\text { deaths that } \\
\text { were HIV } \\
\text { positive }\end{array}$} & \multirow[b]{2}{*}{$\begin{array}{l}\text { Paediatric } \\
\text { in-hospital } \\
\text { mortality } \\
(\%)\end{array}$} \\
\hline & & $\begin{array}{l}\text { Total (\% of all } \\
\text { admissions) }\end{array}$ & $\begin{array}{l}15 \text { months or } \\
\text { below (\% of } \\
\text { HIV tests } \\
\text { positive) }\end{array}$ & $\begin{array}{l}\text { Above } 15 \\
\text { months (\% of } \\
\text { HIV tests } \\
\text { positive) }\end{array}$ & & & & & & & \\
\hline 1992 & 3800 & $120(3)$ & $95(9)$ & $25(5)$ & 9.2 & $1472(39)$ & 5.4 & $2208(58)$ & 3.4 & 6.7 & 4.3 \\
\hline 1993 & 4061 & $228(6)$ & $174(17)$ & $54(10)$ & 12.7 & 1346 (33) & 6.5 & $2487(61)$ & 2.1 & 17.3 & 4.1 \\
\hline 1994 & 4070 & $304(7)$ & $221(26)$ & $83(18)$ & 15.1 & $1003(25)$ & 5.1 & $2763(68)$ & 3.0 & 25.7 & 4.4 \\
\hline 1995 & 4108 & 449 (11) & $355(35)$ & $94(21)$ & 13.8 & $1006(24)$ & 4.0 & $2653(65)$ & 2.9 & 34.8 & 4.3 \\
\hline 1996 & 4694 & $870(19)$ & $644(46)$ & $226(35)$ & 12.9 & $1187(25)$ & 4.5 & $2637(56)$ & 3.0 & 46.1 & 5.2 \\
\hline
\end{tabular}

retrospective data on in-hospital deaths between January 1992 and the end of 1996. Children had HIV tests for clinical indications (using the Centres for Disease Control's 1994 revised classification system $)^{10}$ during the study period. Children at or below 15 months of age were regarded as HIV infected if they had two positive HIV enzyme linked immunosorbent assay (ELISA) tests and features of HIV disease (these include at least two of: generalised lymphadenopathy, hepatomegaly or splenomegaly in the absence of other disease, parotitis, recurrent admissions for common infections, or infections with unusual organisms). Over the age of 15 months children were considered HIV infected with two positive HIV ELISA tests. Children who had HIV ELISA negative tests beyond 15 months were retrospectively allocated a negative HIV status for previous admissions. Fifteen months was used as the cut off as in our experience uninfected children who are unequivocally HIV ELISA positive beyond 15 months of age are rare (G Gray, unpublished data) and many clinicians in this setting will make a definitive diagnosis at this age. Children who tested positive during the study period were allocated a positive status for previous admissions if they had not been tested during previous admissions. It is hospital policy to obtain parental consent and conduct HIV tests with pre- and post-test counselling.

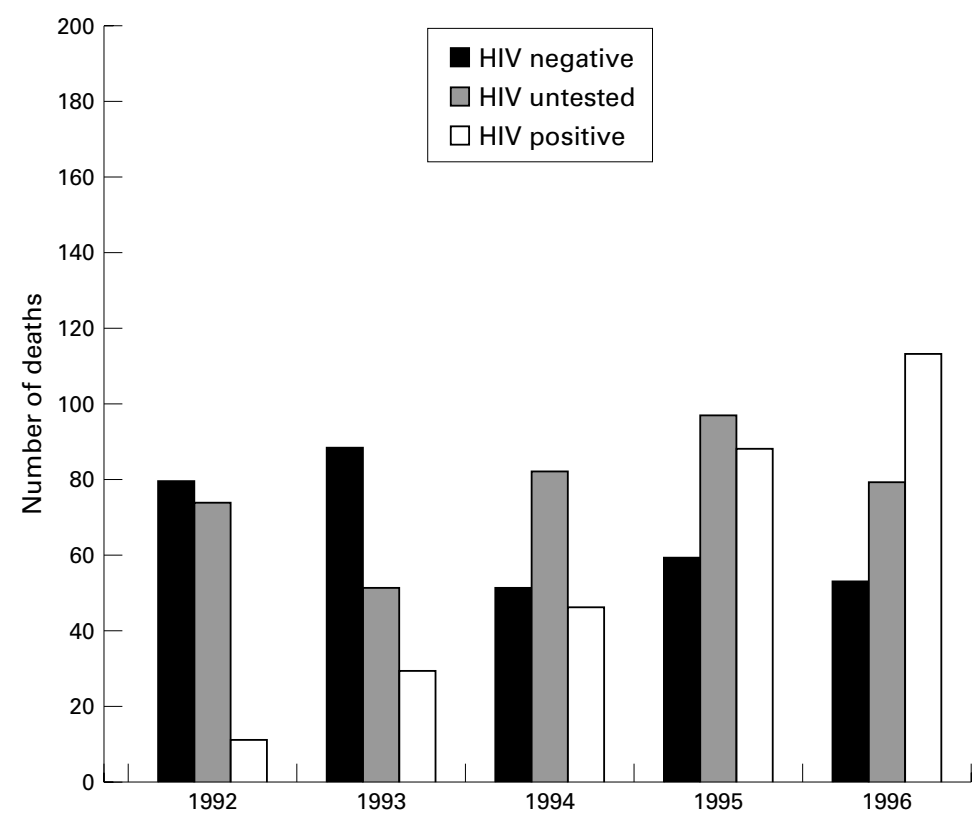

Figure 1 Number of deaths in HIV negative, HIV untested, and HIV positive children by admission year.
STATISTICAL METHODS

The data were analysed using the Statistical Package for the Social Sciences Software Package (SPSS). ${ }^{11}$ Comparisons between groups were made using appropriate statistical methods ( $\chi^{2}$ tests and one way analysis of variance). Trends over time were analysed using the $\chi^{2}$ test for trend.

\section{Results}

Records were available for 20733 paediatric admissions during the study period. Of these, 7985 (39\%) were tested for HIV. There were 120 admissions considered HIV infected in 1992 and 870 by 1996 . Admissions considered infected comprised 3\% of all admissions in 1992 and $19 \%$ of admissions in 1996 (table 1). Of those tested for HIV over the age of 15 months, proportions testing positive increased sevenfold from $4.9 \%$ in 1992 to $35 \%$ in 1996 . For those 15 months and younger the increase was from $9 \%$ to $46 \%$.

A total of 935 children died $(4.5 \%$ of admissions) during the study period, of whom 261 (28\%) were considered HIV infected. In 1992, 11 children considered HIV infected died during their hospital stay; by 1996 this had increased to 113 (fig 1 ). The proportion of all deaths accounted for by HIV infected admissions increased strikingly from $6.7 \%$ in 1992 to $46.1 \%$ in 1996 ( $\mathrm{p}<0.001$ ). HIV infected children had considerably higher in-hospital mortality (13.2\%; odds ratio 2.85$)$ compared with HIV negative $(5.2 \%)$ and untested children $(3.0 \% ; \mathrm{p}<0.001)$. Mortality tended to decline over time in HIV negative children from 5.4\% in 1992 to $4.5 \%$ in 1996 ( $\chi^{2}$ trend 3.3; $\mathrm{p}=0.06)$ while mortality in infected children showed no particular trend. As a consequence of increasing admissions in children considered HIV infected and their high in-hospital mortality rates, overall in-hospital paediatric mortality increased by $21 \%$, from $4.3 \%$ in 1992 to $5.2 \%$ in 1996 .

The most common causes of death in all children irrespective of HIV status were pneumonia, septicaemia, gastroenteritis, and meningitis (table 2). In HIV infected children, pneumonia accounted for a much greater proportion of deaths compared with negative and untested children (54.4\% versus $12.3 \%$; $\mathrm{p}<0.001)$. Gastroenteritis was the next most important cause of death in the infected children, accounting for $12 \%$ of deaths. In HIV negative and untested children, almost half of all deaths were caused by chronic disease and congenital anomalies as opposed to infectious disease; in these children infectious and 
Table 2 Number (\%) of deaths by cause in HIV infected children, HIV negative and untested children, and all children 1992-1996

\begin{tabular}{|c|c|c|c|}
\hline & $\begin{array}{l}\text { HIV positive } \\
(\%)\end{array}$ & $\begin{array}{l}\text { HIV negative } \\
\text { and untested } \\
(\%)\end{array}$ & $\begin{array}{l}\text { All children } \\
(\%)\end{array}$ \\
\hline Pneumonia & $142(54.4)$ & $83(12.3)$ & $225(24.1)$ \\
\hline Gastroenteritis & $30(11.5)$ & $58(8.6)$ & $88(9.4)$ \\
\hline Septicaemia & $24(9.2)$ & $84(12.5)$ & $108(11.6)$ \\
\hline Meningitis & $9(3.4)$ & $40(5.9)$ & $49(5.2)$ \\
\hline
\end{tabular}

nutritional causes of death tended to decline in absolute numbers between 1992 and 1996 .

A greater proportion of infants considered HIV infected died during the first year of life $(16.9 \%)$ compared to uninfected $(6.4 \%)$ and untested children $(3.7 \%)$ ( $<<0.001$; fig 2$)$. Three quarters of these deaths occurred under the age of 6 months in children considered HIV infected. Over the study period, HIV related deaths comprised a progressively greater proportion of deaths in under 1 year olds, from $10 \%$ in 1992 to $52 \%$ in 1996 . The proportional impact of HIV on mortality was greatest for infants. HIV related deaths constituted $36 \%$ of infant deaths compared to $13 \%$ of deaths in 5 year olds.

Case fatality rates were considerably higher for both pneumonia and gastroenteritis in HIV infected children, $19.9 \%$ and $13.7 \%$ respectively, compared to $3.7 \%$ and $2.9 \%$ in the uninfected and untested children $(\mathrm{p}<0.001)$. In the uninfected and untested group there was a decline in case fatality rates for pneumonia between 1992 and 1996 that did not reach statistical significance, from $4.3 \%$ to $3.4 \%\left(\chi^{2}\right.$ trend $2.46 ; \mathrm{p}=0.12)$. For all children, those under the age of 1 year had the highest case fatality for both pneumonia $(6.9 \%)$ and gastroenteritis $(5 \%)$ and this declined with age $\left(\chi^{2}\right.$ trend $26 ; \mathrm{p}<0.001 ; \chi^{2}$ trend $\left.11.3 ; \mathrm{p}=0.001\right)$. HIV infected children were more likely than HIV negative and untested children to have a dual diagnosis of both pneumonia and gastroenteritis $(9.7 \%$ of their admission diagnoses versus $3.7 \%$; $<0.001)$. This group had a case fatality rate of $25 \%$.

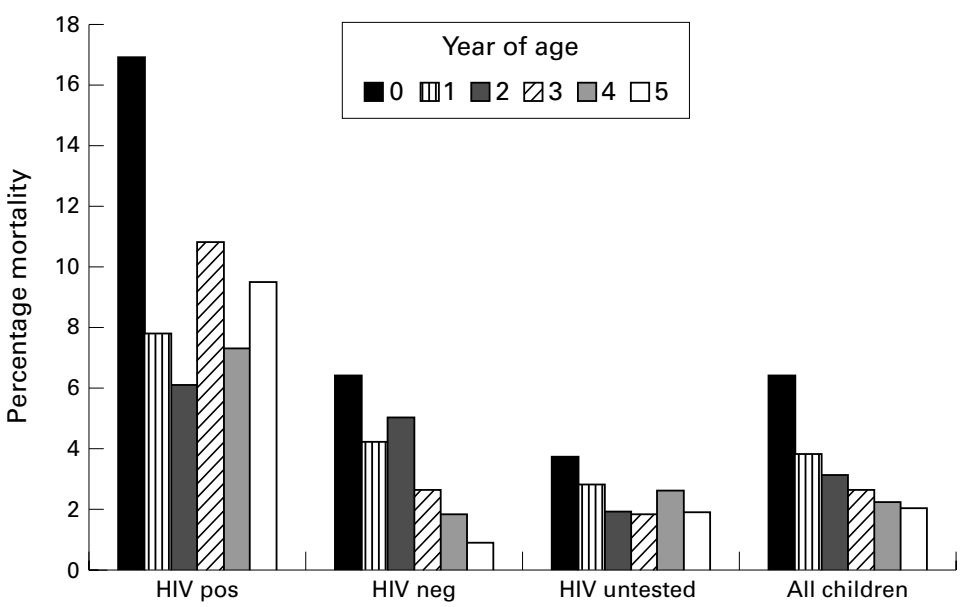

Figure 2 Percentage mortality in HIV positive, HIV negative, HIV untested, and all children by year of age.

\section{Discussion}

This study shows an increase in overall in-hospital paediatric mortality over the five year study period. This is likely to be attributable to HIV infection as all the excess deaths were in children considered HIV infected. This has resulted in a reversal of the trend towards lower rates of in-hospital mortality. By 1996, children considered HIV infected accounted for almost half $(46 \%)$ of all admission deaths. Data available for the first four months of 1997 suggest that the proportion of deaths considered HIV infected is $57 \%$ and that in-hospital mortality has increased to $6.5 \%$, a $51 \%$ rise from 1992. Although the majority of admissions considered HIV infected were at or below 15 months of age, when maternal antibody may be detected by HIV ELISA, clinical criteria were also used to assign HIV status. Those children who subsequently became seronegative were assigned an HIV negative result for preceding admissions. The number of admissions tested for HIV did not alter significantly over the study period, yet the proportion testing positive increased from $4.9 \%$ in 1992 to $35 \%$ in 1996 , even in those older than 15 months, suggesting true increases in prevalence of HIV infected children. The rise in inhospital mortality was most striking in the under 1 year olds. This is probably caused by the high case fatality rates for pneumonia and gastroenteritis in this group, especially if HIV infected. HIV infected children were also more likely to have multiple diagnoses, which increases their mortality risk. Given the young age and high mortality from pneumonia in these young infants, it is likely that many had Pneumocystis carinii pneumonia, ${ }^{12}$ which is largely preventable by early detection of HIV infection and prophylactic medication. In HIV infected children, pneumonia accounted for over half of all deaths and more than four times the proportion caused by gastroenteritis. In negative and untested children, pneumonia was twice as common as gastroenteritis as a cause of death. Access to clean water in the study population probably accounts for the relative importance of pneumonia over gastroenteritis compared with other African study populations. ${ }^{13}$ How in-hospital mortality relates to community mortality rates, which are poorly recorded in South Africa, is an interesting issue. Using annual sentinel survey data of HIV infected antenatal clinic attendees in Soweto, local rates of mother to child transmission, and observed survival curves in infected children, ${ }^{14}$ we have estimated the numbers of children likely to be dying each year in Soweto between 1992 and 1996: 38 in 1992, with a steady increase to 258 in 1996. Looking at CHB hospital deaths in Soweto children only, an increasing proportion of these predicted HIV related deaths occurred in the study hospital over the study period. In 1993 and 1994, for example, $34 \%$ of predicted deaths occurred at $\mathrm{CHB}$, compared with $41 \%$ in 1996 . CHB hospital deaths may underestimate community deaths by as much as $41 \%$, and the relation between hospital and community deaths may change as the epidemic evolves. 
Timaeus $^{5}$ has estimated that under five mortality rates will increase by three per 1000 for every $1 \%$ increase in antenatal seroprevalence (assuming about one third of HIV infected women transmit HIV to their babies). Applying this to South Africa and allowing for a two year delay in the effect of maternal seroprevalence rates on childhood deaths, under five mortality rates would increase from 66 per 1000 to 111 per $1000^{15}$ between 1996 and 2000 (as antenatal seroprevalence increased from $7.9 \%$ in $1994^{1}$ to $22.8 \%$ in $1998^{2}$ ). This represents a $67 \%$ increase, and implies that almost all the advances made since 1960, when the under five mortality was estimated to be 126 per 1000 , would have been reversed. Under five mortality is likely to be the most appropriate measure of the impact of the HIV epidemic on child survival in Africa, as most African children with HIV will die before they turn six. ${ }^{16}$ However in South Africa there continues to be mortality as a result of HIV in the 5-14 year age group, as is beginning to be documented elsewhere ${ }^{17}$ Thus the group that usually experiences the lowest age specific mortality will also feel the impact of the epidemic. Although HIV/AIDS is one of the most important public health problems facing Africa today, we still lack the population data to measure the impact of this epidemic on child survival. In South Africa, accurate infant and child mortality rates are unknown, and classification of death by cause is poorly recorded and likely to be even worse where there is an HIV diagnosis. Hospital data are no replacement for community mortality rates, but the detail available with regard to cause of death, likely accuracy in documenting HIV status, and use of relatively cheap and accessible routine systems make this source an important one for documenting the effects of this epidemic.
1 Department of Health and Population Development, South Africa. Seventh national survey of women attending antenatal clinics of the public health services in South Africa, October/November 1996. Epidemiological Comments 1996;23:4-16.

2 Department of Health and Population Development, South Africa. Ninth national survey of women attending antenatal clinics of the public health services in South Africa, October/November 1998. South Africa: Health Sciences Research and Epidemiology Directorate, Department of Health, 1999.

3 Bobat R, Coovadia H, Coutsoudis A, Moodley D. Determinants of mother-to-child transmission of human immunodeficiency virus type 1 infection in a cohort from Durban, deficiency virus type 1 infection in a cohort from
South Africa. Pediatr Infect Dis $\mathcal{F}$ 1996;15:604-10.

4 Nicoll A, Timaeus I, Kigadye R, Walraven G, Killewo J. The mpact of HIV-1 infection on mortality in children under 5 years of age in sub-Saharan Africa: a demographic and epidemiologic analysis. AIDS 1994;8:995-1005.

5 Timaeus IM. Impact of the HIV epidemic on mortality in sub-Saharan Africa: evidence from national surveys and censuses. AIDS 1998;12(suppl 1):S15-27.

6 Boerma JT, Nunn AJ, Whitworth JAG. Mortality impact of the AIDS epidemic: evidence from community studies in less developed countries. AIDS 1998;12(suppl 1):S3-14.

7 Nunn AJ, Mulder DW, Kamali A, Ruberantwi A, KengeyaKayondo JF, Whitworth J. Mortality associated with HIV-1 infection over five years in a rural Ugandan population: infection over five years in a rural

8 Taha TET, Dallabetta GA, Canner JK, Chiphagwi JD, Taha TET, Dallabetta GA, Canner JK, Chiphagwi JD,
Liomba G, Hoover DR, Miotti P. The effect of human Liomba G, Hoover DR, Miotti P. The effect of human
immunodeficiency virus infection on birth weight, and immunodeficiency virus infection on birth weight, and
infant and child mortality in urban Malawi. Int $\mathcal{f}$ Epidemiol infant and child mo

9 Zwi KJ, Pettifor JM, Soderlund N. Paediatric hospital admissions at a South African urban regional hospital: the mpact of HIV, 1992-1997. Ann Trop Paediatr 1999;19: $135-42$.

10 Centres for Disease Control and Prevention. 1994 revised classification system for human immunodeficiency virus infection in children less than 13 years of age. Mor Mortal Wkly Rep 1994;43:1-19.

11 SPSS for Windows, Version 7.5. Chicago, IL: SPSS Inc., 1996.

12 Jeena PM, Coovadia HM, Chrystal V. Pneumocystis carinii and cytomegalovirus infection in severely ill, HIV-infected and cytomegalovirus infection in severely ill, HIV-

13 Lepage P, Spira R, Kalibala S, et al. Care of human immunodeficiency virus-infected children in developing immunodeficiency virus-infected children in

14 Soderlund N, Zwi KJ, Kinghorn A, Gray G. Prevention of vertical transmission of HIV: analysis of cost effectiveness of options available in South Africa. BMF 1999;318:1650-6.

15 UNICEF. Table 8: The rate of progress. The state of the world's children 1998. New York: Oxford University Press, 1998:126.

16 Marum LH, Tindyebwa D, Gibb D. Care of children with HIV infection and AIDS in Africa. AIDS 1997;11(suppl B):S125-34.

17 Garenne M, Madison M, Tarantola D, Zanou B, Aka J, ogore R. Mortality impact of AIDS in Abidjan, 1986-1992. AIDS 1996;10:1279-86. 